\title{
Strategies of tenogenic differentiation of equine stem cells for tendon repair: current status and challenges
}

\author{
Asiyeh Shojaee ${ }^{1}$ and Abbas Parham ${ }^{1,2^{*}}$ (1)
}

\begin{abstract}
Tendon injuries, as one of the most common orthopedic disorders, are the major cause of early retirement or wastage among sport horses which mainly affect the superficial digital flexor tendon (SDFT). Tendon repair is a slow process, and tendon tissue is often replaced by scar tissue. The current treatment options are often followed by an incomplete recovery that increases the susceptibility to re-injury. Recently, cell therapy has been used in veterinary medicine to treat tendon injuries, although the risk of ectopic bone formation after cell injection is possible in some cases. In vitro tenogenic induction may overcome the mentioned risk in clinical application. Moreover, a better understanding of treatment strategies for musculoskeletal injuries in horse may have future applications for human and vice versa. This comprehensive review outlines the current strategies of stem cell therapy in equine tendon injury and in vitro tenogenic induction of equine stem cell.
\end{abstract}

Keywords: Horse, Tendinopathy, Cell therapy, Stem cell, Cell differentiation, Tissue engineering

\section{Background}

Tendons are dense connective tissues that connect the muscles to the bones and transfer forces generated by the muscles to the bones for locomotion. The extracellular matrix (ECM) of the tendon, which is mainly composed of type I collagen fibrils, is turned over by tenocytes which are responsible for the synthesis of collagen and extracellular

\footnotetext{
* Correspondence: Parham@um.ac.ir

${ }^{1}$ Division of Physiology, Department of Basic Sciences, Faculty of Veterinary Medicine, Ferdowsi University of Mashhad, Mashhad, Iran

${ }^{2}$ Stem Cell Biology and Regenerative Medicine Research Group, Institute of Biotechnology, Ferdowsi University of Mashhad, Mashhad, Iran
}

matrix components [1]. Tenocytes, being terminally differentiated, are elongated cells with extended nuclei within the fascicles. In addition to tenocytes, tendons contain stem/progenitor cells (TSPCs) as roundly shaped with ovidal nucleus between the fascicles. In general, the location of different types of TSPCs is poorly understood and defined but they are most likely limited to endotenon and adjacent to the vasculature [2]. A number of critical transcription factors in tendon development and differentiation have been identified. Scleraxis (SCX) is required for the generation of tendon progenitors whereas Mohawk (MKX) and early growth response 1 and 2 (Egr1/2) are involved in tendon differentiation and the regulation of genes encoding tendon-specific ECM proteins such as COL1, COL3, and TNMD $[3,4]$.

It has been reported that up to $46 \%$ of musculoskeletal injuries are tendon injuries including tendinopathy [5]. Most of the tendinopathy cases have been caused by a combination of intrinsic and extrinsic factors, including age, gender, disease, occupation, and physical training. Tendinopathy consists of a series of reactions caused by physical overuse. If physical overuse persists, eventually, a defective healing response to accumulated micro-injuries led to degenerative tendinopathy. Persistent hypoxia is one of the major drivers of tendinopathy following the upregulation of expression of vascular endothelial growth factor (VEGF) which induces the expression of matrix metalloproteinases (MMPs) resulting in degradation of the tendon matrix [6]. Recently, it has been increasingly accepted that inflammation and degeneration may not be considered to be two separate processes in tendinopathy. Tendinopathy can be classified as either acute, due to excessive overload, or chronic, due to degenerative condition that is persistent over time [7]. A tendinopathy therefore can include tendon injuries such as paratenonitis, tendonitis, and tendinosis [8].

Injury of superficial digital flexor tendon (SDFT) is one of the most frequent causes of lameness and wastage in 
racehorses [9]. The process of tendon healing is slow; this poor healing ability happens due to its hypo-vascularity in tandem with hypo-cellularity. The scar formation and ectopic mineralization after tendon injury can induce rupture in the tendon of predisposed horse and happen through increased expression of collagen type III (COL3) that has smaller fibers and fewer crosslink compared to collagen type I (COL1) leading to inferior mechanical properties $[10,11]$. The current treatment options result in pain relief or replacement of the injured tissue that remained as a clinical challenge to achieve a functional tissue. In recent years, stem cell therapy has received increasing attention as an alternative therapeutic option. The identification and characterization of appropriate sources of cells are required to achieve more effective repair or regeneration of injured tendons.

The objective of the current review is presenting a summary of recent studies in order to inform the reader firstly about various aspects of stem cell therapy for tendon injury in horse and secondly about the current strategies for defining the optimal conditions for in vitro equine tenogenic differentiation.

\section{Use of undifferentiated stem cells for repair of tendon injury}

Bone marrow-derived MSCs

In 2003 for the first time, Smith et al. implanted $6.4 \times$ $10^{5}$ of autologous bone marrow-derived mesenchymal stem cells (BM-MSCs) into SDFT of horse that had suffered a strain-induced injury. There was no observable swelling of the limb and no lameness at the walk; also, the ultrasonographic images revealed the lesion filled with granulation fibrous tissue and no adverse effects in healing tendon was observed; the case study opened the door to further researches. Although most of the clinical investigations has shown promising results of BM-MSC injection into SDFT defects, there are possible disadvantages including painful procedures of BM harvesting, long periods of cell expansion, increasing donor age, passage number that reduces differentiation potential, and possible bone formation following BM-MSC injection $[12,13]$. Moreover, the injection of large volumes of BM not only contains a small number of MSCs but also might disrupt the intact tendon tissue [12].

\section{Adipose tissue-derived mesenchymal stem cells}

Adipose tissue-derived MSCs (ASCs) are the most abundant and accessible source of MSCs. In addition, yielding higher numbers of MSCs derived from equivalent amounts of fat versus bone marrow provides another advantage in using ASCs. ASCs have also attracted great attention as the best candidate for cell therapy due to their ability to produce and secret ECM component and cytokines [14]. For the first time in an animal trial study, the positive influence of ASCs on tendon repair in horse is reported by Nixon et al. [15] as described in Table 1. Moreover, ASCs showed the greatest expression of the component of tendon ECM in comparison with MSCs from other sources and may be a promising cell source for the treatment of equine tendinopathy [33].

\section{Umbilical cord blood-derived MSCs}

Equine MSCs derived from the umbilical cord blood (UCB) or tissue (UCT) were first characterized by Koch et al. [34] and Hoynowski et al. [35]. Although autologous UCB-MSCs need a long initial culture to obtain a sufficient number of MSCs prior to use, allogeneic cultured cells can overcome this limitation as an alternative approach. Therefore, access to allogeneic UCB-MSC banking in analogy with a human can increase the chance of equine cell therapy [36]. In addition to the advantage of non-invasive collection, it has been demonstrated that expression of scleraxis (SCX) is similar to that of tendon-derived MSCs (TDSCs) in undifferentiated, monolayer-cultured at passage 3 [37].

\section{Tendon-derived MSCs}

A current study has shown TDSCs (also known as tendon stem/progenitor cells) as an ideal cell type that displayed tendon-like phenotype and expressed the greatest level of tendon-related markers compared to other sources of MSCs for tendon regeneration [38]. Although using TDSCs showed promising outcomes [32], utilizing them might be limited due to donor site morbidity, inadequate cells that need a long period of culturing, and phenotypic drift during in vitro expansion. To overcome these limitations to some extent, different approaches such as using three-dimensional (3D) culture systems or the addition of growth factors have been reported $[39,40]$.

\section{Embryonic stem-like cells}

Embryonic stem-like cells (ESCs) can provide a source of allogeneic cells for treating tendon injuries in horse. Unlike human and murine ESCs, equine ESCs have not been shown to form teratoma [41]. Although ESCs overcome some practical limitations of autologous MSCs, they require the destruction of an embryo for being isolated [42]. However, the clinical potential of ESC in the treatment of tendon injuries is revealed, and the absence of tumorigenic deviations of these cells remains to be studied in longer follow-ups [28, 43]. It has recently been suggested that the ethical and legal issues of ESCs for clinical application can be overcome by induced pluripotent stem cells (iPSCs). IPSCs maintain an epigenetic memory of their origin; it can adversely affect their differentiation potential. The generation of iPSCs from equine fibroblasts constitutes an important step toward the understanding of pluripotency in horse and a clinical tool in veterinary 


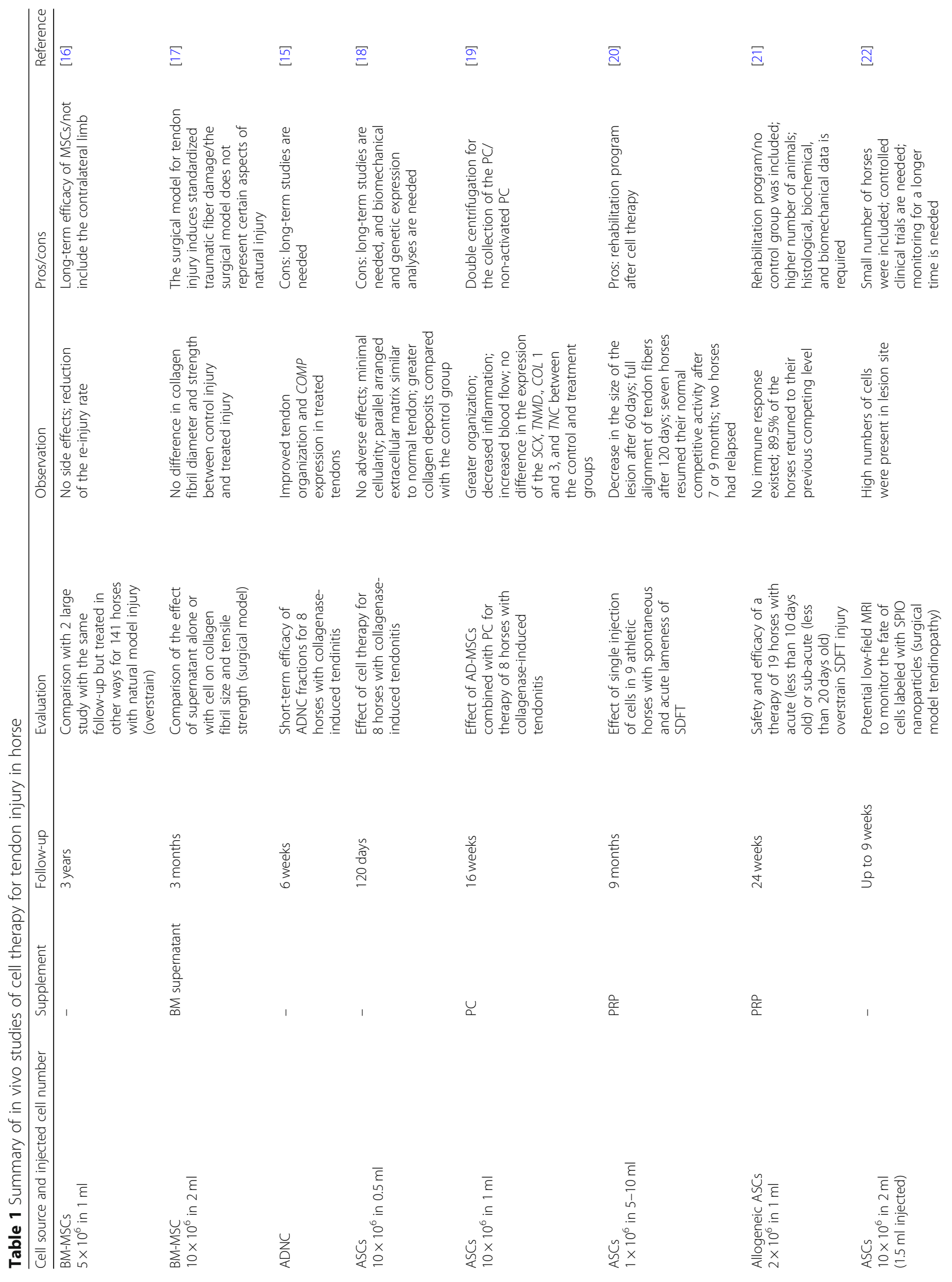




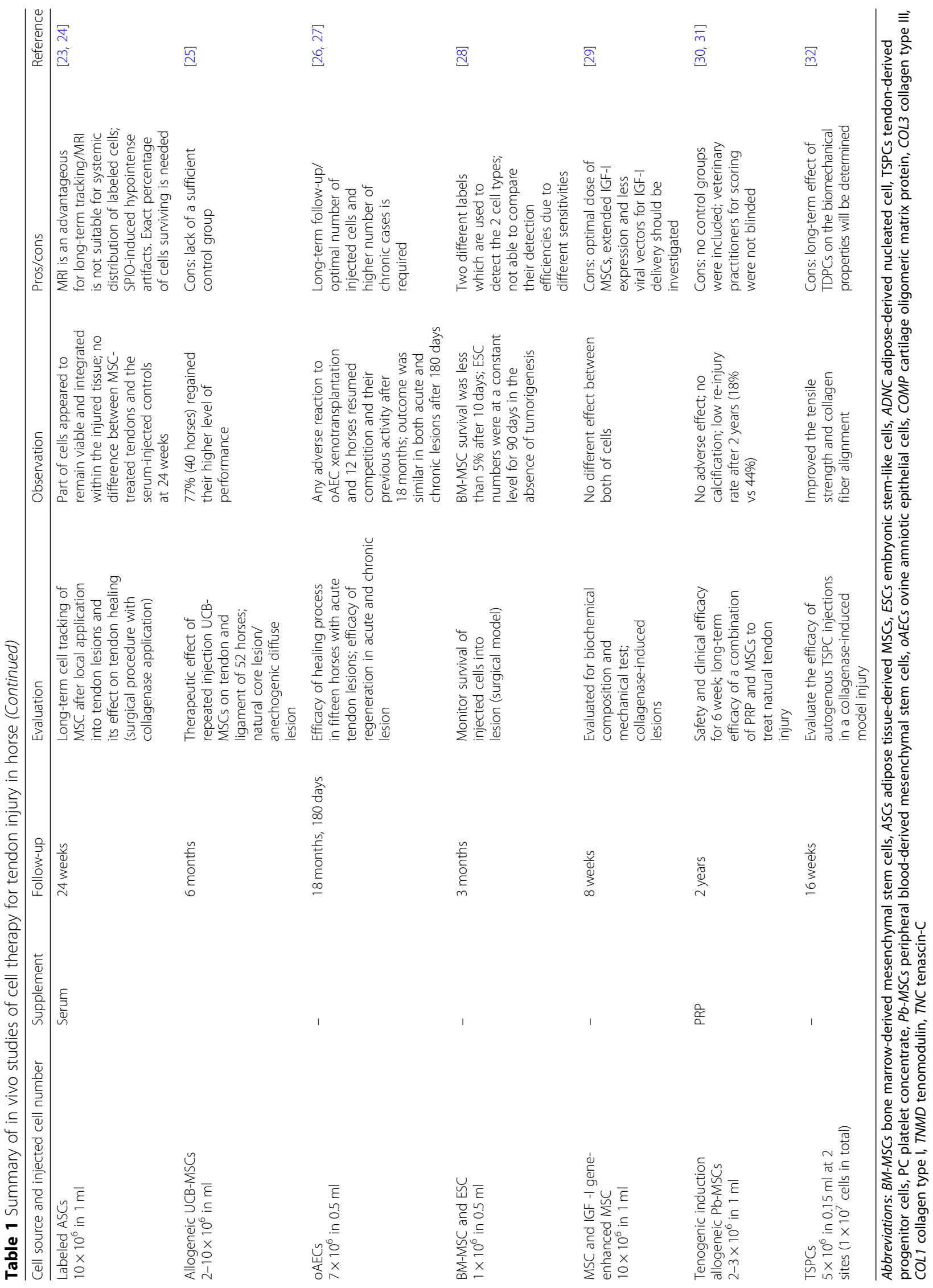


biomedicine [44, 45]. Moreover, their ability to differentiate into tendon cells has been demonstrated [5].

Taking together, equine MSCs derived from the adipose tissue, umbilical cord blood, and many other tissues are promising candidates in regenerative medicine. Implantation of MSCs can recruit the other MSCs or progenitor cells toward injury site since they produce a variety of cytokines and paracrine factors to improve the regeneration potential [46].

\section{Challenges of stem cell therapy in equine tendon injury}

Although the application of stem cells for tendon healing is promising, some challenges should be considered in this field. Efficacy of equine MSC therapy is difficult to be evaluated, and it depends on the use of appropriate control groups, the severity and size of the lesion, time between injury and implantation, number of stem cell for implantation, models of tendinopathy (e.g., collagenase or surgical disruption), and opting for single or multiple injection. Intralesional injection of a cell suspension is the common approach since the tendon lesions are typically located in the center of SDFT [47]. Depending on the size and the severity of lesion, the number of stem cells and the volume of cell suspension should be estimated prior to injection. It has been suggested that numbers of MSCs from 10 to $50 \times 10^{6}$ and the injection volume less than $1 \mathrm{ml}$ are required to prevent damage to fibers due to compression [48]. It has been demonstrated that the best time for cell therapy is after the inflammatory phase [12]. The number of injection sites depends on the distribution of the injected cells, the type of the cells, and the level of damage observed ultrasonographically [16]. In addition, immunomodulatory effects of MSCs are dose and time dependent, so that different outcomes are reported after single or repeated injection [49-52]. There are some concerns about the use of direct injection of aspirated heterogeneous mixed cell, for instance a small number of stem cells in a large volume might disrupt remaining intact tendon tissue; therefore, concentration of aspirate would overcome this limitation to some extent [12]. Also, cell culture technique is helpful for re-implantation of large numbers of MSC [53]. Although transporting the cells to clinic, the handling step in clinic and injection process including sheer stress caused by needle wall, needle size, and the use of other tools for injection influence post-injection cell viability and differentiation potential by increasing the number of dead or damaged cells [54]. Twenty-four hours after injection, more of half of labeled cells are lost, which may enter the blood circulation due to damages in blood vessels by injection process and relocate to other injury sites $[23,55,56]$. Therefore, selection of the implantation technique as well as reliable techniques for tracking of transplanted cells is still challenging.
Though some studies have a control group, the limited sample size in horse studies and the inter-animal variability of the pathological conditions influence outcomes. Furthermore, some cases are mixed with other biological factors such as BM supernatant [17], autologous serum, platelet-rich plasma (PRP) [19], and genetically modified MSCs [29]. Extensive in vivo studies have been conducted on cell therapy for tendon injury in the horse (Table 1).

\section{Various strategies for in vitro tenogenic differentiation of equine stem cells}

The result of MSC therapy can be affected by the use of undifferentiated or differentiated MSCs for tendon repair since the risk of ectopic bone formation after undifferentiated MSC injection in tendon has been reported $[57,58]$. To avoid the abovementioned risk, MSCs would be induced toward tenogenic differentiation before clinical application [30, 31]. Figure 1 demonstrates a schematic view on our understanding for improving the tendon regeneration potential in horse. In vitro differentiated stem cells could possibly result in faster regeneration after application [31]. In addition, it has been demonstrated that $24 \%$ of injected MSCs were retained at the site of injury after $24 \mathrm{~h}$ and most of the MSCs migrate from the site of injury after transplantation which might be directed to non-tenocyte differentiation in the in vivo condition [55]. Different strategies have been described to improve the ability of MSC and target sites to better respond to the homing stimuli and recruitment of stem cells respectively [59]. Here, we describe different strategies of recent findings that are often a combination of different strategies for tenogenic differentiation of equine stem cells.

\section{Growth factors}

Growth factors (GFs) are important signaling molecules, involving tendon development and differentiation, which are produced at various stages of tendon healing [60]. The effect of exogenous addition of GFs to cell culture media, which trigger tenogenic differentiation, is influenced by the delivery of a single or multiple GF, incubation time, and cell type. Moreover, proper doses of GFs need to be determined in order to achieve better results. It should be noticed that small variations in concentrations of the GFs can result in considerably different effects [61]. In addition, they have a short half-life, which necessitates repeated dosing that poses costly challenge in their clinical application. Table 2 summarizes the results of in vitro experiments that investigated the role of GFs on tenogenic differentiation of various stem cells in horse. 


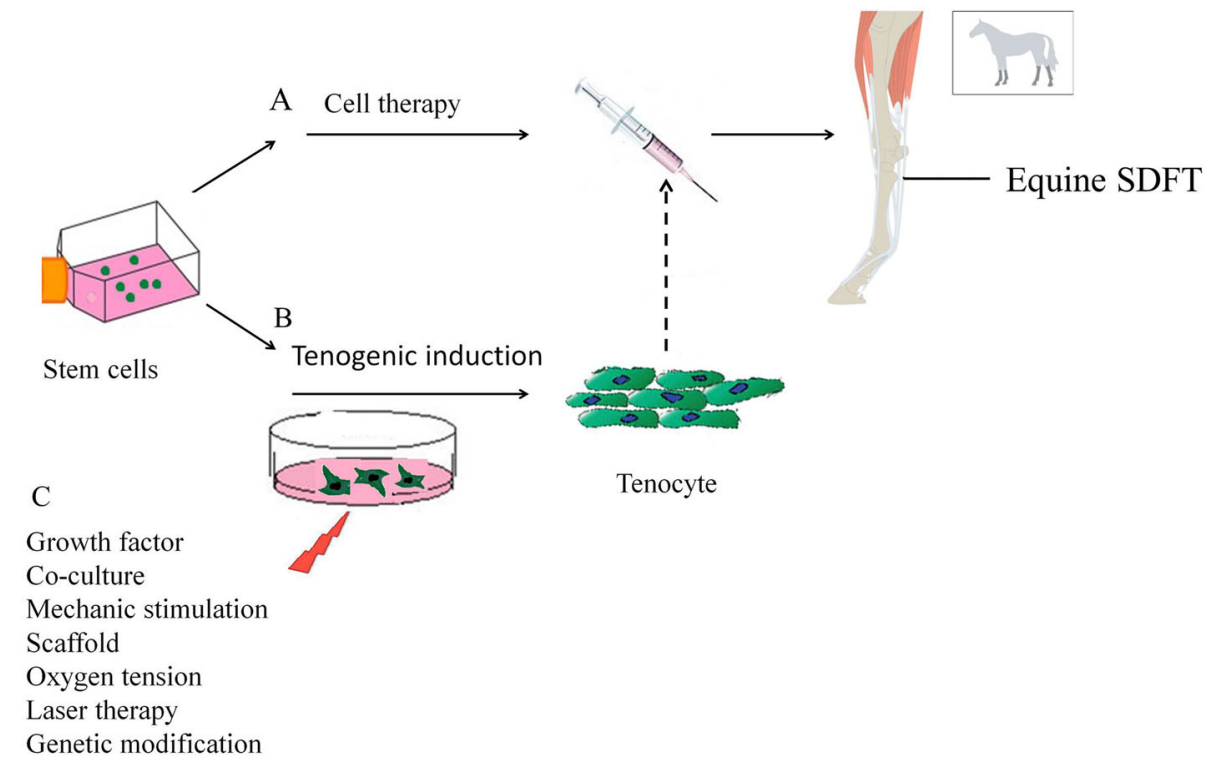

Fig. 1 Schematic overview of the Cell therapy based on utilizing undifferentiated stem cells (a) or differentiated stem cells (b) through various strategies (c) for tendon injury in horse. Dash line indicated possible applications of differentiated stem cells under different strategies for tenogenic differentiation

\section{Co-culture system}

Tendon regeneration can occur either via the ability of MSCs to differentiate into tenocytes within the tissue or via trophic factors produced by MSCs, or a combination of these two mechanisms [48]. The first study on co-culture in equine species was reported by Lovati et al. [70]. They demonstrated that indirect co-culture of equine BM-MSCs with tendon for 2 weeks could induce tenogenic differentiation. Probably, the paracrine factors released by tendon could be responsible for the observed effect.

Lange-Consiglio et al. [71] also highlighted the paracrine effect of possible mechanisms for tendon healing process. They investigated the effect of immunomodulatory of equine amniotic membrane-derived MSCs (AMCs) both in direct and indirect co-culture systems and demonstrated that AMCs inhibit the proliferation of equine peripheral blood mononuclear cells (PBMCs) after allogeneic stimulation in both culture systems. They suggested that secreted factors of the conditioned medium (CM) are responsible for the anti-proliferative effect; therefore, no cell-to-cell contact was required. Moreover, injection of AMC-CM in spontaneous tendon injuries in horse showed no adverse effect such as fibrotic, metaplastic, or mineralization. In addition, the re-injury rate was lower in comparison with untreated cases after 2 years.

A recent study demonstrated that co-culture of ovine amniotic epithelial cells (oAECs) with adult equine tendon started to aggregate and formed three-dimensional bundle structure after 28 days with fusiform-aligned cells, while oAECs cultured alone reached a confluent monolayer. Furthermore, analyses by reverse transcription polymerase chain reaction (RT-PCR) showed similar expression of COL1, SCX, and COL3 in oAEC co-culture compared to ovine tendons [26].

\section{Various scaffold parameters}

It is well-known that ECM not only provides a mechanical support for cells but also regulates cell behavior. In addition, cells are responsible for secreting ECM components; thus, ECM is dynamic [72]. Recently, in vitro studies, which have mimicked the dynamic nature of the ECM, have tried to improve scaffold designing to promote tenogenic differentiation of equine stem cells as described here.

\section{Scaffold substrate materials and biomolecule presentation}

A primary effort in the development of regenerative medicine is the choice of an appropriate biomaterial scaffold being able to mimic native ECM for providing an environment to speed healing or regeneration. Biologic scaffold materials generate chemotactic molecules through scaffold degradation process to the recruitment of stem cells. Not only that, they have shown to alter the local innate immune response, which contributes to tissue repair and scaffold remodeling [47]. Reed et al. [73] investigated the effect of three different substrates on tenogenic differentiation and showed equine UCB-MSCs and ASCs cultured 
Table 2 Summary of in vitro studies on tenogenic differentiation by growth factors in horse

\begin{tabular}{|c|c|c|c|c|c|}
\hline Growth factor & Concentration & Other modification & Cell source & Outcome & Reference \\
\hline TGFB3 & $20 \mathrm{ng} / \mathrm{ml}$ & $2 \mathrm{D}$ and $3 \mathrm{D}$ cultures & Tenocytes and ESCs & $\begin{array}{l}\text { Unlike tenocytes, ESCs } \\
\text { upregulated tendon } \\
\text { markers in 2D culture } \\
\text { and showed synergic } \\
\text { effect with TGFB3 and } \\
\text { 3D; no cartilage or bone } \\
\text { tissue deposition }\end{array}$ & {$[41,62]$} \\
\hline TGFB3 & $20 \mathrm{ng} / \mathrm{ml}$ & 3D collagen gel & IPS & $\begin{array}{l}\text { Reduced expression of } \\
\text { tendon-related marker } \\
\text { of iPSCs in 3D versus 2D } \\
\text { culture }\end{array}$ & [5] \\
\hline BMP12 & $50 \mathrm{ng} / \mathrm{ml}$ & & AF-MSCS & $\begin{array}{l}\text { Elongated and spindle- } \\
\text { shaped; expressed } \\
\text { TNMD and DCN genes }\end{array}$ & [63] \\
\hline BMP12 & $50 \mathrm{ng} / \mathrm{ml}$ & & BM-MSCS & $\begin{array}{l}\text { Elongated tenocyte-like } \\
\text { phenotype; expressed } \\
\text { TNMD and DCN genes }\end{array}$ & [64] \\
\hline BMP12 & $50 \mathrm{ng} / \mathrm{ml}$ & & UCB-MSCS & $\begin{array}{l}\text { Expression of SCX, MKX, } \\
\text { TNM, COL } 1 \text {, and DCN by } \\
\text { RT-PCR; expression of } \\
\text { protein TNM, DCN }\end{array}$ & [65] \\
\hline $\begin{array}{l}\text { TGFB3, EGF2, } \\
\text { bFGF2, IGF-1 }\end{array}$ & $10 \mathrm{ng} / \mathrm{ml}$ & LLLT & PB-MSCs & $\begin{array}{l}\text { Supplementation with } \\
\text { bFGF2 and TGFB3 } \\
\text { upregulated expression } \\
\text { of EGR1, and DCN; } \\
\text { increased TNC with LLLT }\end{array}$ & [66] \\
\hline $\begin{array}{l}\text { PDGF-BB, IGF-1, bFGF, } \\
\text { SDF-1 a, and GDF-5 }\end{array}$ & $\begin{array}{l}5,50,5,50 \text { and } 100 \mathrm{ng} / \mathrm{ml} \\
\text { respectively }\end{array}$ & Scaffold & Tenocytes & $\begin{array}{l}\text { Effect of pairing IGF-1, } \\
\text { GDF- } 5 \text { rescue the tenocyte } \\
\text { phenotype and gene } \\
\text { expression profiles and } \\
\text { driving proliferation }\end{array}$ & [67] \\
\hline TGFB1, IGF-1, insulin & $10 \mathrm{ng} / \mathrm{ml}$ and $50 \mathrm{ng} / \mathrm{ml}$ & 2D and 3D cultures & Tenocyte & $\begin{array}{l}\text { Pro-tenogenic effect with } \\
3 \mathrm{D} \text { culture system treated } \\
\text { with GFs }\end{array}$ & [40] \\
\hline GDF5, GDF6 and GDF7 & $10 \mathrm{ng} / \mathrm{ml}$ and $100 \mathrm{ng} / \mathrm{ml}$ & $\begin{array}{l}\text { Strain stimulation; } \\
\text { oxygen tension }\end{array}$ & AD-MSC & $\begin{array}{l}\text { Expression of tendon- } \\
\text { relevant genes were } \\
\text { higher with an oxygen } \\
\text { tension of } 21 \% \text {, tensile } \\
\text { stimulation and } \\
\text { supplementation } \\
\text { with GDF5 or GDF } 7\end{array}$ & [68] \\
\hline |GF-1 & $100 \mathrm{ng} / \mathrm{ml}$ & $\begin{array}{l}\text { Acellular tendon } \\
\text { matrix }\end{array}$ & BM-MSCs and TDSCs & $\begin{array}{l}\text { COL and GAG syntheses } \\
\text { were higher in TDSCs; no } \\
\text { significant difference was } \\
\text { observed in the expression } \\
\text { of COL1, COL3, and COMP } \\
\text { between BM-MSCs and } \\
\text { TDSCs }\end{array}$ & [69] \\
\hline TGFB3 & $2.5 \mathrm{ng} / \mathrm{ml}$ & $\begin{array}{l}\text { Treated with Gremlin } \\
\text { and SOST; nanofiber } \\
\text { scaffold }\end{array}$ & ASCs & $\begin{array}{l}\text { Increased tenogenic } \\
\text { markers; decreased } \\
\text { osteo-chondrogenic } \\
\text { markers treated with } \\
\text { T/G/S on nanofiber } \\
\text { scaffold }\end{array}$ & Our unpublished data \\
\hline
\end{tabular}

Abbreviations: TGF- $\beta$ transforming growth factor, BMP bone morphogenetic protein, EGF epidermal growth factor, $b F G F$ fibroblast growth factor, IGF-1 insulin-like growth factor, $P D G F-B B$ platelet-derived growth factor-BB, GDF growth and differentiation factor, SDF-1 stromal cell-derived factor-1, EGR1 early growth response protein 1, DCN decorin, COL3A1 collagen type III, COL1A1 collagen type I, TNMD tenomodulin, T/G/S TGFB3/Gremlin/SOST, LLLT low-level laser therapy

on gelatin-coated plasticware, $30 \%$ matrigel or collagencoated beads and treated with a different isomer of fibroblast growth factor (FGF) increased SCX expression on matrigel, especially in ASCs. However, the regulation of tenogenic gene expression in response to FGF stimulation is considerably different in the two cell types. 
Interactions of growth factors and ECM in regulating the repair process are important. Many of these growth factors have been utilized either in the form of bound to the extracellular matrix (in the sequestered form) or freely soluble in it. Immobilizing the proteins is important to develop long-term tissue engineering solutions for controlling the growth factor delivery, particularly when increased diffusion or internalization of factors and reduced stability biomolecules are observed due to their short half-life [74, 75]. The effect of delivery method (e.g., soluble, sequestered) of five biomolecules on the behavior of equine tenocytes seeded on anisotropic collagen-glycosaminoglycan (CG) scaffold in tendon regeneration applications showed that sequestration can lead to a greater sustained bioactivity compared to soluble supplementation [40].

\section{Three-dimensional scaffolds}

As discussed previously, a critical drawback of prolonged in vitro culturing of tenocytes is the loss of differentiated function. It has been revealed that three-dimensional (3D) culture system prevents cellular de-differentiation to some extent. In this regard, Theiss and colleagues [40] showed that 3D microtissue system maintains the tenocyte phenotype in vitro. They also demonstrated that equine tenocytes retained a more differentiated state when scaffold-free micro tissue spheroids were embedded in collagen gels.

Barsby et al. [62] indicated that 3D culture enhanced tenogenic differentiation of equine ESCs seeded into 3D anchored collagen in comparison with 2D. In addition, equine tenocytes and ESCs are able to form constructs resembling artificial tendon by contraction of the matrix. Moreover, treatment with transforming growth factor (TGFB3) increased the initial rate of contraction and had a synergic effect on the upregulation of tendonassociated gene expression in 3D ESC culture, while the presence or absence of TGFB3 had no effect on contraction rate of tenocyte constructs. Although they did not compare tendon-related marker expression in $2 \mathrm{D}$ and $3 \mathrm{D}$ culture for equine tenocytes, it seems that 3D culture could keep the expression of tendon-associate proteins constant for long-term culture [41, 62]. Comparing the functional tendon differentiation of iPSCs with ESCs in $3 \mathrm{D}$ culture system by the same group showed that ESCs and iPSCs treated with TGFB3 in 2D culture system upregulated tendon-related genes; however, iPSCs delayed in comparison to ESCs. Furthermore, in contrast to ESCs, expression of tendon-associated genes with the exception of COL1 was not detected in iPSCs seeded on constructs and failed to generate artificial tendons. They suggested that one of the reasons is epigenetic differences between iPSCs and ESCs [5].
Decellularization of tendon tissue provides a 3D scaffold with a native ECM and a similar structure and topography to the tendon. Different protocols for decellularization of tendon tissue by using physical or chemical methods have been investigated [76]. Comparison of some tendon extracellular matrix markers of the cells isolated from equine bone marrow, tendon, and muscle on tendon matrix showed that COL1 expression was similar among different cell sources and TDSCs expressed highest COL3 expression [77].

\section{Scaffold micro-nano structure}

Mechanical properties of scaffold at the macro- and micro-scales are known to influence the cellular behaviors. Accordingly, 3D culture is important to prevent tenocytes de-differentiating within 2D culture. Recently, it has been revealed that phenotype of tenocytes is lost within 3D scaffold. Maintaining a high degree of anisotropy in scaffold to prevent altering cell fate due to loss of structural stability via cell-mediated contractile forces is a challenge in tendon tissue engineering [78]. The anisotropic CG scaffold with high crosslinking densities and small pore sizes indicated the increase in bioactivity of equine tenocytes and resistance to contraction as well as an increase and maintenance in expression of tenogenic markers for long-term culture [39].

The nanoscale topography is another factor in scaffold designing which indicated good results on tenogenic differentiation. Popielarczyk et al. [79] investigated the effect of topography on tenogenesis and showed that nanofiber topography alone can influence the tenogenic differentiation of equine BM-MSCs. Upregulation in the expression of tenogenic genes and production of ECM component was observed in aligned nanofiber scaffold with both a parallel and perpendicular oriented fibrous.

As mentioned previously, typical equine tendon lesions are located in the center of the SDFT surrounded by almost intact tendon tissue. Therefore, the choice of a scaffold, delivery of which into equine tendon injury is easy, should be considered; further studies are needed in the future.

\section{Mechanical stimulation}

The mechanical stimulation is a major parameter in tendon biology. Conversion of mechanical stimulus into a biomechanical signal results in cell proliferation, differentiation, and ECM synthesis. Different physical environmental factors, from substrate stiffness to dynamic mechanical loading, in the form of static tension or cyclic axial stimulation, may regulate tenogenic stem cell differentiation [1, 80]. Depending on the stimulation regime, mechanical stress can induce tenogenic or osteogenic differentiation of stem cells. Raabe et al. [68] examined the influence of strain as the sole factor or in 
combination with other factors (GFs and $\mathrm{O} 2$ tension) in equine ASCs cultured on collagen I gel scaffold. The results of uniaxial tensile strain versus no mechanical stimulation showed tendon-like morphology with an alignment of cells and matrix in the collagen I gel construct. In addition, comparing the three cyclic strain (0,3, and 5\%) on tenogenic differentiation made by Youngstrom et al. [81], equine BM-MSCs seeded on decellularized tendon scaffold under 3\% cyclic strain showed an increased expression of $S C X, C O L 1$, decorin $(D C N)$, and biglycan, as well as increased ratio of relative COL1 to COL3, and an increase in elastic modulus and ultimate tensile strength of construct. However, cyclic axial strain can also increase the expression of osteogenic markers. In this respect, equine ASCs were seeded on decellularized tendon matrix under static and $2 \%$ cyclic strain with different stimulation regime, which showed upregulation of expression of osteopontin, COL3, and $D C N$ and downregulation of COL1 in all of the groups compared to that of the monolayer control group. Although the expression of $S C X$ at the last time point was upregulated slightly, a significant increase was observed under a short period of mechanical stimulation. They found that the difference between gene expression in their study and the findings of Youngstrom et al. is associated with the time points of gene expression analysis. They also showed that tendon matrix synthesis and tenogenic differentiation were under moderate mechanical stimulation regimes [82].

\section{Laser therapy}

Low-level laser therapy (LLLT) is a modality to reduce inflammation and pain and to accelerate tissue healing. There is little literature on the controversial outcome of the use of LLLT for equine tendinopathy. The interpretation of in vivo outcomes is considerably difficult due to many intervening variables. Recently, several studies have investigated the in vitro effect of laser irradiation on the cellular behavior; it depends on laser light wavelength, energy density, and cell type [83, 84]. Irradiating equine PB-MSCs with a 660-nm wavelength laser indicated no significant difference in proliferation and differentiation versus the control group, although combination of some growth factors with LLLT arrested cell proliferation and enhanced tenogenic differentiation in comparison with the other group. The co-treatment of PB-MSCs with bFGF2 and TGFB3 without LLLT significantly increased the expression of early growth response protein-1 (EGR1) and DCN, while the synergistic effect of GFs with LLLT significantly increased expression of EGR1, DCN, and Tenascin C [66].

\section{Genetically modified cells}

Several in vitro studies have investigated the role of gene products in tendon healing by gene delivery growth factors, transcription factors, and non-coding RNA into equine stem cells.

BMP12 has been established as a tenogenic growth factor, and a promising finding of equine stem cells treated with recombinant BMP12 protein is presented in Table 2. Furthermore, early cellular effects of equine tenocytes and BM-MSCs transfected with BMP12 and BMP2 were observed in response to BMP12. The upregulation of COL1 and cartilage oligomeric matrix protein (COMP) expression was the greatest in tenocytes treated with BMP12 compared to BM-MSCs, and no mineralization detected in both cell types. It suggested that BMP12 gene delivery might induce early differentiation in early tendon healing [85].

The role of microRNA (miRNA) has been revealed in tendinopathy and tendon injury healing. In this regard, Millar et al. [86] indicated that the expression of COL3 was upregulated in tendinopathy. By contrast, miR-29a expression was significantly downregulated. Additionally, in vitro transferring of miR-29a into equine tenocytes showed the reduced expression of COL3. Moreover, inhibition of miR-29a upregulated the expression of COL3. In fact, miR-29a plays an important role in the regulation of COL3 expression in tendinopathy. Accordingly, the condition medium of AMCs decreases the pro-inflammatory genes and appears to demonstrate promising in vivo results for tendon healing. Indeed, miRNAs, identified in microvesicles secreted by equine AMCs, are responsible for these effects [87].

SCX is a well-known transcription factor in tendon development and differentiation, while it has been recently reported that SCX has a distinct role in different stages of development and in different cell types. Knockdown of SCX reduced the expression of COL1, COMP, and $S O X 9$ in fetal tenocytes, while it made no significant changes in the expression of their genes in adult tenocytes in 2D. Furthermore, adult tenocytes transfected with shSCX contracted the 3Dcollagen gel, while fetal tenocytes and ESCs failed to generate artificial tendon following SCX knockdown. SCX overexpression in fetal tenocytes, in which SCX had been knocked down formerly, reversed these effects [88].

As described above, the upregulation of expression of $S C X$ was observed after physiological loading, but its mechanoresponse is not well defined. Recently, one study identified the novel role of SCX in modulating cytoskeletal tension. Equine tenocytes transfected with SCX siRNA decreased cytoskeletal stiffness by changing the focal adhesion-related gene expression and resulted in an inability to migrate on the soft surface [89].

\section{Oxygen tension}

It is well known that oxygen $\left(\mathrm{O}_{2}\right)$ tension depends on species, source of tissue, and other factors influencing the cell behavior. Although the physiological condition 
is hypoxic in some tissues, in vitro culture condition is routinely normoxic and needs further studies for standardization of the cell culture [90, 91]. The first analysis of the influence of oxygen tension on the behavior of equine MSCs showed that hypoxia reduces the proliferative capacity of cells, while it does not have any effect on the phenotype of cells, and it appears to keep them more undifferentiated [90].

Comparison of the influence of normoxic and hypoxic conditions (3\% versus $21 \% \mathrm{O}_{2}$ tension) on tenogenic differentiation of ASCs indicated that the cell morphology was more tendon-like under $21 \% \mathrm{O}_{2}$, while the gene expression of the tendon-relevant markers revealed no significant differences. The gene expression of COL1 was higher under $21 \% \mathrm{O}_{2}$ than $3 \% \mathrm{O}_{2}$. Cells were almost damaged under hypoxic conditions [68].

\section{Conclusion}

Taken together, despite the wide range of studies, translating basic findings to clinical applications is limited; it is due to some concerns about the risk of bone, tumor, and scar formation. To fill the gap between experimental research and clinical applications, reliable and specific markers for the identification of tenocytes as well as conducting non-randomized studies with long-term follow-up periods are deemed necessary for further evaluation of the efficacy and safety of tendon injury. Finally, there are great resemblances between equine superficial digital flexor tendon and human Achilles tendon in the size of anatomical structure and load, function (energy store), pathophysiology of tendon injury, and the healing response under activity or traumatic rupture compared to other species [11, 92]. Moreover, considering the result of induced tendinopathy in equine species which reflects the conditions encountered in human, horse is accepted as an appropriate model in this area by research community and other authorities such as the US Food and Drug Administration (FDA) and the European Medicines Agency (EMA) [93]. Moreover, the high-level analogy between human and equine MSCs may have a great translational value for both species for future clinical aspects $[93,94]$. As summarized in this review, utilizing tenogenically induced MSCs through pretreatment with bioactive compounds and applying other in vitro strategies may increase cell survival and the efficacy of cell therapy for tendon repair. Most of the success achieved in cell therapy in horses with core lesions in SDFT has been observed following the intralesional injection due to granulation tissue and the enclosed nature of core lesions that may have provided an appropriate scaffold. Therefore, for other forms of damaged tendon (eccentric lesions), future studies should optimize cell dose, time, and route of injection since accurate injection placement and retention of cells are more problematic [53]. In this case, the use of delivery vehicle such as different types of scaffold or selforganizing tendon (3D tendon-like tissue constructs) may improve stem cell retention at the site of injury with regard to ensuring that implantation of cells should occur within $24 \mathrm{~h}$ of resuspension in culture. In addition, it should be considered that the individual differences such as age, genetic factors, and donor health status affect the properties of MSCs [95]. Hence, the complete molecular analysis of MSCs in order to their modification seems to be highly necessary before the clinical application.

\section{Abbreviations}

AMCs: Amniotic membrane-derived MSCs; ASCs: Adipose tissue-derived MSCs; BM-MSCs: Bone marrow-derived mesenchymal stem cells;

CM: Conditioned medium; ESCs: Embryonic stem-like cells; FGF: Fibroblast growth factor; GFs: Growth factors; iPSCs: Induced pluripotent stem cells;

LLLT: Low-level laser therapy; OAECs: Ovine amniotic epithelial cells;

TDSCs: Tendon-derived MSCs; TGFB3: Transforming growth factor;

UCB: Umbilical cord blood

\section{Acknowledgements}

Not applicable

Authors' contributions

ASH wrote the first draft, and AP modified and finalized the manuscript. Both authors have read and approved the final submitted manuscript.

\section{Funding}

Not applicable

\section{Availability of data and materials}

The sources for the information discussed in this review can be obtained from the papers cited in the references.

Ethics approval and consent to participate

Not applicable

Consent for publication

Not applicable

Competing interests

The authors declare that they have no competing interests.

Published online: 18 June 2019

\section{References}

1. Nourissat G, Berenbaum F, Duprez D. Tendon injury: from biology to tendon repair. Nat Rev Rheumatol. 2015;11:223.

2. Schneider $M$, Angele $P$, Jarvinen $T A H$, Docheva D. Rescue plan for Achilles: therapeutics steering the fate and functions of stem cells in tendon wound healing. Adv Drug Deliv Rev. 2018;129:352-75.

3. Liu H, Zhu S, Zhang C, Lu P, Hu J, Yin Z, et al. Crucial transcription factors in tendon development and differentiation: their potential for tendon regeneration. Cell Tissue Res. 2014;356:287-98.

4. Subramanian A, Schilling TF. Tendon development and musculoskeletal assembly: emerging roles for the extracellular matrix. Development. 2015; 142:4191-204.

5. Bavin EP, Smith O, Baird AEG, Smith LC, Guest DJ. Equine induced pluripotent stem cells have a reduced tendon differentiation capacity compared to embryonic stem cells. Front Vet Sci. 2015;2:55.

6. Tempfer $\mathrm{H}$, Traweger $\mathrm{A}$. Tendon vasculature in health and disease. Front Physiol. 2015;6:330.

7. Walden G, Liao X, Donell S, Raxworthy MJ, Riley GP, Saeed A. A clinical, biological, and biomaterials perspective into tendon injuries and regeneration. Tissue Eng Part B Rev. 2017;23:44-58. 
8. Manske RC. Tendinopathy. In: Giangarra CE, Manske RC, editors. Clinical orthopaedic rehabilitation: a team approach. 4th ed: Elsevier Health Sciences; 2018. p. 601-4. https://doi.org/10.1016/B978/-0-323-39370-6.00084-6.

9. Thorpe $C T$, Clegg PD, Birch HL. A review of tendon injury: why is the equine superficial digital flexor tendon most at risk? Equine Vet J. 2010;42:174-80.

10. O'Brien EJO, Smith RKW. Mineralization can be an incidental ultrasonographic finding in equine tendons and ligaments. Vet Radiol Ultrasound. 2018. https://doi.org/10.1111/vru.12628.

11. Patterson-Kane JC, Becker DL, Rich T. The pathogenesis of tendon microdamage in athletes: the horse as a natural model for basic cellular research. J Comp Pathol. 2012;147:227-47.

12. Fortier LA, Smith RKW. Regenerative medicine for tendinous and ligamentous injuries of sport horses. Vet Clin North Am Equine Pract. 2008;24:191-201.

13. Koch TG, Berg LC, Betts DH. Current and future regenerative medicineprinciples, concepts, and therapeutic use of stem cell therapy and tissue engineering in equine medicine. Can Vet J. 2009:50:155.

14. Pascucci L, Alessandri G, Dall'Aglio C, Mercati F, Coliolo P, Bazzucchi C, et al. Membrane vesicles mediate pro-angiogenic activity of equine adiposederived mesenchymal stromal cells. Vet J. 2014;202:361-6.

15. Nixon AJ, Dahlgren LA, Haupt JL, Yeager AE, Ward DL. Effect of adiposederived nucleated cell fractions on tendon repair in horses with collagenase-induced tendinitis. Stem Cell Res Ther. 2008;69:928-37.

16. Godwin EE, Young NJ, Dudhia J, Beamish IC, Smith RKW. Implantation of bone marrow-derived mesenchymal stem cells demonstrates improved outcome in horses with overstrain injury of the superficial digital flexor tendon. Equine Vet J. 2012;44:25-32.

17. Caniglia CJ, Schramme MC, Smith RK. The effect of intralesional injection of bone marrow derived mesenchymal stem cells and bone marrow supernatant on collagen fibril size in a surgical model of equine superficial digital flexor tendonitis. Equine Vet J. 2012;44:587-93.

18. de Mattos Carvalho A, Alves ALG, de Oliveira PGG, Alvarez LEC, Amorim RL, Hussni CA, et al. Use of adipose tissue-derived mesenchymal stem cells for experimental tendinitis therapy in equines. J Equine Vet Sci. 2011;31:26-34

19. Carvalho AM, Badial PR, alvarez LEC, Yamada ALM, Borges AS, Deffune E, et al. Equine tendonitis therapy using mesenchymal stem cells and platelet concentrates: a randomized controlled trial. Stem Cell Res Ther. 2013;4:85.

20. Guercio A, Di Marco P, Casella S, Russotto L, Puglisi F, Majolino C, et al. Mesenchymal stem cells derived from subcutaneous fat and platelet-rich plasma used in athletic horses with lameness of the superficial digital flexor tendon. J Equine Vet Sci. 2015;35:19-26.

21. Ricco S, Renzi S, Del Bue M, Conti V, Merli E, Ramoni R, et al. Allogeneic adipose tissue-derived mesenchymal stem cells in combination with platelet rich plasma are safe and effective in the therapy of superficial digital flexor tendonitis in the horse. Int J Immunopathol Pharmacol. 2013;26:61-8.

22. Geburek F, Mundle K, Conrad S, Hellige M, Walliser U, van Schie HTM, et al. Tracking of autologous adipose tissue-derived mesenchymal stromal cells with in vivo magnetic resonance imaging and histology after intralesional treatment of artificial equine tendon lesions-a pilot study. Stem Cell Res Ther. 2016;7:21.

23. Burk J, Berner D, Brehm W, Hillmann A, Horstmeier C, Josten C, et al. Long-term cell tracking following local injection of mesenchymal stromal cells in the equine model of induced tendon disease. Cell Transplant. 2016;25:2199-211.

24. Ahrberg AB, Horstmeier C, Berner D, Brehm W, Gittel C, Hillmann A, et al. Effects of mesenchymal stromal cells versus serum on tendon healing in a controlled experimental trial in an equine model. BMC Musculoskelet Disord. 2018;19:230.

25. Van Loon VJF, Scheffer CJW, Genn HJ, Hoogendoorn AC, Greve JW. Clinical follow-up of horses treated with allogeneic equine mesenchymal stem cells derived from umbilical cord blood for different tendon and ligament disorders. Vet Q. 2014;34:92-7.

26. Muttini A, Valbonetti L, Abate M, Colosimo A, Curini V, Mauro A, et al. Ovine amniotic epithelial cells: in vitro characterization and transplantation into equine superficial digital flexor tendon spontaneous defects. Res Vet Sci. 2013;94:158-69.

27. Muttini A, Russo V, Rossi E, Mattioli M, Barboni B, Tosi U, et al. Pilot experimental study on amniotic epithelial mesenchymal cell transplantation in natural occurring tendinopathy in horses. Ultrasonographic and histological comparison. Muscles Ligaments Tendons J. 2015;5:5.

28. Guest DJ, Smith MRW, Allen WR. Equine embryonic stem-like cells and mesenchymal stromal cells have different survival rates and migration patterns following their injection into damaged superficial digital flexor tendon. Equine Vet J. 2010;42:636-42.

29. Schnabel LV, Lynch ME, Van Der Meulen MCH, Yeager AE, Kornatowski MA, Nixon AJ. Mesenchymal stem cells and insulin-like growth factor-l geneenhanced mesenchymal stem cells improve structural aspects of healing in equine flexor digitorum superficialis tendons. J Orthop Res. 2009;27:1392-8.

30. Beerts C, Suls M, Broeckx SY, Seys B, AI V, Declercq J, et al. Tenogenically induced allogeneic peripheral blood mesenchymal stem cells in allogeneic platelet-rich plasma: 2-year follow-up after tendon or ligament treatment in horses. Front Vet Sci. 2017:4:158.

31. Broeckx S, Zimmerman M, Aerts D, Seys B, Suls M, Marien T, et al. Tenogenesis of equine peripheral blood-derived mesenchymal stem cells: in vitro versus in vivo. J Tissue Sci Eng. 2012;11:1-6.

32. Durgam SS, Stewart AA, Sivaguru M, Wagoner Johnson AJ, Stewart MC. Tendon-derived progenitor cells improve healing of collagenase-induced flexor tendinitis. J Orthop Res. 2016;34:2162-71.

33. Burk J, Gittel C, Heller S, Pfeiffer B, Paebst F, Ahrberg AB, et al. Gene expression of tendon markers in mesenchymal stromal cells derived from different sources. BMC Res Notes. 2014;7:826.

34. Koch TG, Heerkens $T$, Thomsen PD, Betts DH. Isolation of mesenchymal stem cells from equine umbilical cord blood. BMC Biotechnol. 2007;7:26.

35. Hoynowski SM, Fry MM, Gardner BM, Leming MT, Tucker JR, Black L, et al. Characterization and differentiation of equine umbilical cord-derived matrix cells. Biochem Biophys Res Commun. 2007;362:347-53.

36. De Schauwer C, Van de Walle GR, Van Soom A, Meyer E. Mesenchymal stem cell therapy in horses: useful beyond orthopedic injuries? Vet $Q$. 2013;33:234-41.

37. Burk J, Ribitsch I, Gittel C, Juelke H, Kasper C, Staszyk C, et al. Growth and differentiation characteristics of equine mesenchymal stromal cells derived from different sources. Vet J. 2013;195:98-106.

38. Youngstrom DW, LaDow JE, Barrett JG. Tenogenesis of bone marrow-, adipose-, and tendon-derived stem cells in a dynamic bioreactor. Connect Tissue Res. 2016;57:454-65

39. Grier WK, lyoha EM, Harley BAC. The influence of pore size and stiffness on tenocyte bioactivity and transcriptomic stability in collagen-GAG scaffolds. J Mech Behav Biomed Mater. 2017;65:295-305.

40. Theiss F, Mirsaidi A, Mhanna R, Kummerle J, Glanz S, Bahrenberg G, et al. Use of biomimetic microtissue spheroids and specific growth factor supplementation to improve tenocyte differentiation and adaptation to a collagen-based scaffold in vitro. Biomaterials. 2015;69:99-109.

41. Barsby T, Guest D. Transforming growth factor beta3 promotes tendon differentiation of equine embryo-derived stem cells. Tissue Eng Part A. 2013; 19:2156-65.

42. Saito S, Ugai H, Sawai K, Yamamoto Y, Minamihashi A, Kurosaka K, et al. Isolation of embryonic stem-like cells from equine blastocysts and their differentiation in vitro1. FEBS Lett. 2002;531:389-96.

43. Watts $A E$, Yeager AE, Kopyov OV, Nixon AJ. Fetal derived embryonic-like stem cells improve healing in a large animal flexor tendonitis model. Stem Cell Res Ther. 2011;2:4

44. Breton A, Sharma R, Diaz AC, Parham AG, Graham A, Neil C, et al. Derivation and characterization of induced pluripotent stem cells from equine fibroblasts. Stem Cells Dev. 2012;22:611-21.

45. Nagy K, Sung H-K, Zhang P, Laflamme S, Vincent P, Agha-Mohammadi S, et al. Induced pluripotent stem cell lines derived from equine fibroblasts. Stem Cell Rev. 2011;7:693-702

46. Mundra V, Gerling IC, Mahato RI. Mesenchymal stem cell-based therapy. Mol Pharm. 2012;10:77-89.

47. Burk J, Badylak SF, Kelly J, Brehm W. Equine cellular therapy-from stall to bench to bedside? Cytometry A. 2013;83:103-13.

48. Alves LG, de Mattos Carvalho A, A Hussni C. Mesenchymal stem cell therapy for equine tendinitis. Recent Pat Regen Med. 2013;3:103-10.

49. Geburek F, Lietzau M, Beineke A, Rohn K, Stadler PM. Effect of a single injection of autologous conditioned serum (ACS) on tendon healing in equine naturally occurring tendinopathies. Stem Cell Res Ther. 2015;6:126.

50. Guest DJ, Smith MRW, Allen WR. Monitoring the fate of autologous and allogeneic mesenchymal progenitor cells injected into the superficial digital flexor tendon of horses: preliminary study. Equine Vet J. 2008;40:178-81.

51. AI V, Broeckx SY, Beerts C, Seys B, Zimmerman M, Verweire I, et al. Tenogenically induced allogeneic mesenchymal stem cells for the treatment of proximal suspensory ligament desmitis in a horse. Front Vet Sci. 2015;2:49 
52. Geburek F, Roggel F, van Schie HTM, Beineke A, Estrada R, Weber K, et al. Effect of single intralesional treatment of surgically induced equine superficial digital flexor tendon core lesions with adipose-derived mesenchymal stromal cells: a controlled experimental trial. Stem Cell Res Ther. 2017;8:129

53. Smith RKW, Korda M, Blunn GW, Goodship AE. Isolation and implantation of autologous equine mesenchymal stem cells from bone marrow into the superficial digital flexor tendon as a potential novel treatment. Equine Vet J. 2003:35:99-102

54. Garvican ER, Cree S, Bull L, Smith RKW, Dudhia J. Viability of equine mesenchymal stem cells during transport and implantation. Stem Cell Res Ther. 2014;5:1

55. Becerra P, Valdas Vazquez MA, Dudhia J, Fiske-Jackson AR, Neves F, Hartman $N G$, et al. Distribution of injected technetium 99 m-labeled mesenchymal stem cells in horses with naturally occurring tendinopathy. J Orthop Res. 2013;31:1096-102.

56. Sole A, Spriet M, Padgett KA, Vaughan B, Galuppo LD, Borjesson DL, et al. Distribution and persistence of technetium-99 hexamethyl propylene amine oxime-labelled bone marrow-derived mesenchymal stem cells in experimentally induced tendon lesions after intratendinous injection and regional perfusion of the equine distal limb. Equine Vet J. 2013;45:726-31.

57. Fang Z, Zhu T, Shen WL, Tang QM, Chen JL, Yin Z, et al. Transplantation of fetal instead of adult fibroblasts reduces the probability of ectopic ossification during tendon repair. Tissue Eng Part A. 2012;20:1815-26.

58. Harris MT, Butler DL, Boivin GP, Florer JB, Schantz EJ, Wenstrup RJ. Mesenchymal stem cells used for rabbit tendon repair can form ectopic bone and express alkaline phosphatase activity in constructs. J Orthop Res. 2004;22:998-1003.

59. De Becker A, Van Riet I. Homing and migration of mesenchymal stromal cells: how to improve the efficacy of cell therapy? World J Stem Cells 2016:8:73.

60. James R, Kesturu G, Balian G, Chhabra AB. Tendon: biology, biomechanics, repair, growth factors, and evolving treatment options. J Hand Surg Am. 2008;33:102-12

61. Torricelli P, Fini M, Filardo G, Tschon M, Pischedda M, Pacorini A, et al. Regenerative medicine for the treatment of musculoskeletal overuse injuries in competition horses. Int Orthop. 2011;35:1569-76.

62. Barsby T, Bavin EP, Guest DJ. Three-dimensional culture and transforming growth factor beta3 synergistically promote tenogenic differentiation of equine embryo-derived stem cells. Tissue Eng Part A. 2014;20:2604-13.

63. Gulati BR, Kumar R, Mohanty N, Kumar P, Somasundaram RK, Yadav PS. Bone morphogenetic protein-12 induces tenogenic differentiation of mesenchymal stem cells derived from equine amniotic fluid. Cells Tissues Organs. 2013;198:377-89.

64. Violini S, Ramelli P, Pisani LF, Gorni C, Mariani P. Horse bone marrow mesenchymal stem cells express embryo stem cell markers and show the ability for tenogenic differentiation by in vitro exposure to BMP-12. BMC Cell Biol. 2009;10:29.

65. Mohanty N, Gulati BR, Kumar R, Gera S, Kumar P, Somasundaram RK, et al. Immunophenotypic characterization and tenogenic differentiation of mesenchymal stromal cells isolated from equine umbilical cord blood. In Vitro Cell Dev Biol Anim. 2014;50:538-48.

66. Gomiero C, Bertolutti G, Martinello T, Van Bruaene N, Broeckx SY, Patruno M, et al. Tenogenic induction of equine mesenchymal stem cells by means of growth factors and low-level laser technology. Vet Res Commun. 2016;40:39-48.

67. Caliari SR, Harley BAC. Composite growth factor supplementation strategies to enhance tenocyte bioactivity in aligned collagen-GAG scaffolds. Tissue Eng Part A. 2013;19:1100-12.

68. Raabe O, Shell K, Fietz D, Freitag C, Ohrndorf A, Christ HJ, et al. Tenogenic differentiation of equine adipose-tissue-derived stem cells under the influence of tensile strain, growth differentiation factors and various oxygen tensions. Cell Tissue Res. 2013;352:509-21.

69. Durgam SS, Stewart AA, Pondenis HC, Gutierrez-Nibeyro SM, Evans RB, Stewart MC. Comparison of equine tendon-and bone marrow-derived cells cultured on tendon matrix with or without insulin-like growth factor-1 supplementation. Am J Vet Res. 2012;73:153-61.

70. Lovati AB, Corradetti B, Cremonesi F, Bizzaro D, Consiglio AL. Tenogenic differentiation of equine mesenchymal progenitor cells under indirect coculture. Int J Artif Organs. 2012;35:996-1005.

71. Lange-Consiglio A, Rossi D, Tassan S, Perego R, Cremonesi F, Parolini O. Conditioned medium from horse amniotic membrane-derived multipotent progenitor cells: immunomodulatory activity in vitro and first clinical application in tendon and ligament injuries in vivo. Stem Cells Dev. 2012;22:3015-24.

72. Gattazzo F, Urciuolo A, Bonaldo P. Extracellular matrix: a dynamic microenvironment for stem cell niche. Biochim Biophys Acta Gen Subj. 2014;1840:2506-19.

73. Reed SA, Johnson SE. Expression of scleraxis and tenascin C in equine adipose and umbilical cord blood derived stem cells is dependent upon substrata and FGF supplementation. Cytotechnology. 2014;66: 27-35.

74. Ker EDF, Chu B, Phillippi JA, Gharaibeh B, Huard J, Weiss LE, et al. Engineering spatial control of multiple differentiation fates within a stem cell population. Biomaterials. 2011;32:3413-22

75. Wilgus TA. Growth factor-extracellular matrix interactions regulate wound repair. Adv Wound Care. 2012;1:249-54.

76. Burk J, Erbe I, Berner D, Kacza J, Kasper C, Pfeiffer B, et al. Freeze-thaw cycles enhance decellularization of large tendons. Tissue Eng Part C Methods. 2013;20:276-84.

77. Stewart AA, Barrett JG, Byron CR, Yates AC, Durgam SS, Evans RB, et al, Comparison of equine tendon-, muscle-, and bone marrow-derived cells cultured on tendon matrix. Am J Vet Res. 2009;70:750-7.

78. Caliari SR, Weisgerber DW, Ramirez MA, Kelkhoff DO, Harley BAC. The influence of collagen-glycosaminoglycan scaffold relative density and microstructural anisotropy on tenocyte bioactivity and transcriptomic stability. J Mech Behav Biomed Mater. 2012;11:27-40.

79. Popielarczyk TL, Nain AS, Barrett JG. Aligned nanofiber topography directs the tenogenic differentiation of mesenchymal stem cells. Appl Sci. 2017:7:59.

80. Schiele NR, Marturano JE, Kuo CK. Mechanical factors in embryonic tendon development: potential cues for stem cell tenogenesis. Curr Opin Biotechnol. 2013;24:834-40.

81. Youngstrom DW, Rajpar I, Kaplan DL, Barrett JG. A bioreactor system for in vitro tendon differentiation and tendon tissue engineering. J Orthop Res. 2015:33:911-8.

82. Burk J, Plenge A, Brehm W, Heller S, Pfeiffer B, Kasper C. Induction of tenogenic differentiation mediated by extracellular tendon matrix and short-term cyclic stretching. Stem Cells Int. 2016;2016(Article ID 7342379):11. http://dx.doi.org/10.1155/2016/7342379.

83. Peat FJ, Colbath AC, Bentsen LM, Goodrich LR, King MR. In vitro effects of high-intensity laser photobiomodulation on equine bone marrow-derived mesenchymal stem cell viability and cytokine expression. Photomed Laser Surg. 2018;36:83-91.

84. Husby KA. In vitro evaluation of therapeutic laser treatment on equine tendon fibroblasts; 2016.

85. Murray SJ, Santangelo KS, Bertone AL. Evaluation of early cellular influences of bone morphogenetic proteins 12 and 2 on equine superficial digital flexor tenocytes and bone marrow-derived mesenchymal stem cells in vitro. Am J Vet Res. 2010;71:103-14.

86. Millar NL, Watts AE, Akbar M, Hughes T, Kitson S, Gilchrist DS. MicroRNA-29a in equine tendinopathy-a translational target. Equine Vet J. 2016;48:27.

87. Lange-Consiglio A, Lazzari B, Perrini C, Pizzi F, Stella A, Cremonesi F, et al. MicroRNAs of equine amniotic mesenchymal cell-derived microvesicles and their involvement in anti-inflammatory processes. Cell Transplant. 2018;27:45-54.

88. Bavin EP, Atkinson F, Barsby T, Guest DJ. Scleraxis is essential for tendon differentiation by equine embryonic stem cells and in equine fetal tenocytes. Stem Cells Dev. 2017;26:441-50.

89. Nichols AEC, Settlage RE, Werre SR, Dahlgren LA. Novel roles for scleraxis in regulating adult tenocyte function. BMC Cell Biol. 2018;19:14.

90. Ranera B, Remacha AR, Avarez-Arguedas S, Romero A, Vazquez FJ, Zaragoza $P$, et al. Effect of hypoxia on equine mesenchymal stem cells derived from bone marrow and adipose tissue. BMC Vet Res. 2012;8:142.

91. Shell K, Raabe O, Freitag C, Ohrndorf A, Christ H-J, Wenisch S, et al. Comparison of equine adipose tissue-derived stem cell behavior and differentiation potential under the influence of 3\% and 21\% oxygen tension. J Equine Vet Sci. 2013;33:74-82.

92. Lui PPY, Maffulli N, Rolf C, Smith RKW. What are the validated animal models for tendinopathy? Scand J Med Sci Sports. 2011;21:3-17.

93. Hillmann A, Ahrberg AB, Brehm W, Heller S, Josten C, Paebst F, et al. Comparative characterization of human and equine mesenchymal stromal 
cells: a basis for translational studies in the equine model. Cell Transplant. 2016;25:109-24.

94. Zahedi M, Parham A, Dehghani H, Mehrjerdi HK. Stemness signature of equine marrow-derived mesenchymal stem cells. Int I Stem Cells. 2017;10:93.

95. Kornicka K, Houston J, Marycz K. Dysfunction of mesenchymal stem cells isolated from metabolic syndrome and type 2 diabetic patients as result of oxidative stress and autophagy may limit their potential therapeutic use. Stem Cell Rev. 2018;14:337-45.

\section{Publisher's Note}

Springer Nature remains neutral with regard to jurisdictional claims in published maps and institutional affiliations. 